\title{
The exercise prescription
}

Do you remember the story about cardiac non-disease in children? ${ }^{1,2}$ You should, as it is a great example of good medical and parental intentions to care going wrong.

In that paper $^{2}$ researchers studied and followed-up a group of school children who had been diagnosed as having an 'innocent' heart murmur. The parents had been fully reassured about the innocence of the murmur. Yet the children with the diagnosis were treated as 'fragile' and 'vulnerable' and in need of extra care. They were 'protected' from taking a fully active part in games, and ended up as disabled as children who had significant structural heart lesions.

At the opposite extreme, one of the authors (Peter Davies) remembers going out climbing with a friend at university. At lunchtime his friend calmly pulled out his insulin syringe and injected himself. Up till then he had had no idea that his friend was diabetic. To his friend, diabetes was simply something he dealt with. The friend was considerably stronger and fitter than Dr Davies.

Two papers in this issue raise the question of what we should tell people with chronic illnesses about exercise. The first is about asthmatic school children in Dundee, and their own, their parents', and their teachers' perceptions of their ability to take part in physical activity. ${ }^{3}$ From this paper it is clear that there are many false limiting beliefs among these children about their asthma, some of which arise from what we as doctors have told them. Is this another example of a way in which doctors can create iatrogenic harm?

On the plus side, some parents and children did recall being encouraged to exercise by doctors and practice nurses. Even then the advice was not always well tailored and specific to the patient. As so often in disease management we find inconsistent recommendations by professionals and inconsistent understanding by children and parents. This is despite the existence of clear national guidelines on exercise prescription. ${ }^{4}$ The net result is that many children with asthma are not participating actively in sports, and so are missing the opportunity to build up their fitness and exercise capacity which would actually help them manage their asthma better, ${ }^{5}$ as well as being good for their general health and morale. ${ }^{6-8}$

Moving south, the second paper is from Edinburgh and is about diabetics and exercise. ${ }^{9}$ This is an older group of patients, who may well have developed their diabetes as a result of previously sedentary lifestyles. This paper carefully explores patients' attitudes to exercise, and what forms of activity are sustainable, and can be incorporated into a patient's life, and which forms have no traction or attraction for patients. The basic message is that activity that has an external point, such as walking a dog, or walking with a friend, is more likely to be sustained than purely personal activity, such as going to the gym. ${ }^{10}$

To a large extent, the people for whom general strength and fitness is valuable in itself are already doing exercise throughout their lives, and mostly are avoiding type 2 diabetes mellitus. Those who are inactive and so on the way towards developing type 2 diabetes need some persuading to become active.

In the UK in 2010 we are in an odd position with regard to exercise. This oddness applies at the level of population health, and is reflected in doctors' consulting rooms. It is entirely natural, from an evolutionary perspective, for humans to be active. Human beings are also 'human doings', and the physical activity we do has a substantial effect on what we become. As a human society, and as individuals, we have arrived at a situation whereby exercise is seen as something unusual and abnormal, and as additional or extrinsic to normal life. The default has become one of inactivity, and what should be an entirely usual part of life has become separated from daily activity. The office world of jumping to conclusions and running ideas up the flagpole is not a recognisable form of exercise!

We have a massive knowing-doing gap between what we, whether professional or lay, all know about exercise and health and our doing anything with that knowledge. We live in a post-industrial, knowledge economy and forget that to keep our knowledge machines running we need a healthy body to support it.? Given this disconnection, what should the NHS, as a system, and we as individual GPs be doing about this gap?

The Department of Health has been very active on this topic, producing much well written and evidenced guidance $e^{4,8}$ over many years. Primary care trusts (PCTs) and local councils have collaborated to create exercise referral schemes. Whether these are effective or not is far from clear, particularly when taking a long-term perspective. ${ }^{10}$ At least they get some people started. The National Institute for Health and Clinical Excellence (NICE) has produced some guidelines on brief interventions that primary care practitioners can use to encourage patients towards physical activity. ${ }^{11}$

In the surgery, recommending exercise is a classic low-cost health promotion activity per quality-adjusted life year. It is like smoking cessation advice: quick and cheap to give, and even if most of its recipients ignore it, if it nudges one or two patients in the right direction, they get a significant individual health gain, and the NHS system saves a lot on future care costs. The costs of inactivity to the NHS are significant, being estimated at about $£ 5$ million per PCT in England in 2006. ${ }^{12}$ We can feel our opportunistic health promotion spiel getting longer and becoming, 'You do know that you should stop smoking, drink less, and exercise more?'

We wonder how many Quality and Outcomes Framework points we will get for that in future. As GPs, we could do worse than to heed the key points of Sir Liam Donaldson's last annual report, ${ }^{13}$ in which he stated that inactivity affects $60-70 \%$ of the adult population and physical fitness of children has declined by $9 \%$ per decade. That means the 
majority of our patients are inactive.

Inactive lifestyle predisposes people to six major diseases: coronary heart disease, stroke, type 2 diabetes, colon cancer, breast cancer, and osteoporosis. ${ }^{4,8}$ Importantly, while physical activity tends to decline with age, this is behavioural and cultural rather than biological inevitability. Exercise throughout life does reduce the risk of illness and injury; for example, by reducing the risk of falls in older people.

If our patients do show any interest then do we know exactly what to recommend? NICE recommends that GPs should be assessing their patients' activity levels and then providing tailored specific advice to each patient. ${ }^{11}$ It is good advice, but it will be yet another thing that GPs are ideally placed to do, and then systematically fail to achieve. It is doubtful that most doctors and practice nurses know exactly what exercise to recommend to which patient, ${ }^{14}$ and this may be one reason why exercise recommendations are neglected in clinical contexts where they could be helpful to patients, such as diabetes mellitus. ${ }^{15}$

As practitioners we do need to rethink our thoughts and actions about exercise. It is clear that exercise is good for health and human flourishing. It both prevents many diseases and it also helps those with established disease to recover more effectively and function better. It is drugfree, easily available, and mostly low risk, especially at moderate to low intensities. Exercise should be a normal part of everyone's life, and as doctors we, along with others, should be encouraging it. And this is advice we should apply to ourselves, so that we are good examples, rather than dire warnings, to our patients.

\section{Peter Davies,}

GP, Keighley Road Surgery, Illingworth, Halifax.

\section{Gerard Garbutt}

Visiting Professor of Clinical Exercise Science, Calderdale Royal Hospital, Pennine Vocational Training scheme Learning \& Development Centre, Halifax.

\section{Provenance}

Commissioned; not peer reviewed.

\section{REFERENCES}

1. [No authors listed]. Morbidity of cardiac 'non-disease' in school children. Can Med Assoc J 1967; 97(24): 1490-1491.

2. Bergman AB, Stamm SJ. The morbidity of cardiac nondisease in schoolchildren. N Engl J Med 1967; 276(18): 1008-1013.

3. Williams B, Hoskins G, Pow J, et al. Low exercise among children with asthma: a culture of over protection? A qualitative study of experiences and beliefs. Br J Gen Pract 2010; DOI:

10.3399/bjgp10X515070 (abridged text, in print: $\mathrm{Br}$ J Gen Pract 2010; 60: 578-583).

4. Department of Health. At least five a week: Evidence on the impact of physical activity and its relationship to health. London: Department of Health, 2004 http://www.dh.gov.uk/en/Publicationsandstatistics/Publ ications/PublicationsPolicyAndGuidance/DH_4080994 (accessed 30 Jun 2010).

5. Asthma UK. Exercise. London: Asthma UK. http://www.asthma.org.uk/all_about_asthma/healthy_li festyles/exercise.html (accessed 30 Jun 2010).

6. Davies PG. Between health and illness. Perspect Biol Med 2007; 50(3): 444-452.

7. Ratey JJ, Hagerman E. Spark: how exercise will improve the performance of your brain. London: Quercus, 2009.

8. Department of Health. Let's Get Moving — introducing a new physical activity care pathway. London:

Department of Health, 2010

http://www.dh.gov.uk/en/Publichealth/Healthimprove ment/PhysicalActivity/DH_099438 (accessed 30 Jun 2010).

9. Peel E, Douglas M, Parry O, Lawton J. Type 2 diabetes and dog walking: patients' longitudinal perspectives about implementing and sustaining physical activity. $\mathrm{Br}$ $J$ Gen Pract 2010; 60: 570-577.

10. Williams NH, Hendry M, France B, et al. Effectiveness of exercise-referral schemes to promote physical activity in adults: systematic review. Br J Gen Pract 2007; 57(545): 979-986.

11. National Institute for Health and Clinical Excellence. Four commonly used methods to increase physical activity. London: NICE, 2006. http://guidance.nice.org.uk/PH2/Guidance/pdf/English (accessed 30 Jun 2010).

12. Department of Health. Detailed local area costs of physical inactivity by disease category. London: Department of Health, 2009.

http://www.dh.gov.uk/prod_consum_dh/groups/dh_di gitalassets/documents/digitalasset/dh_105888.pdf (accessed 30 Jun 2010).

13. Donaldson L. On the state of public health: annual report of the Chief Medical Officer. London: Department of Health, 2010.

14. Blair SN, LaMonte MJ. How much and what type of physical activity is enough? What physicians should tell their patients. Arch Intern Med 2005; 165(20): 2324-2325.

15. Praet SF, van Loon LJ. Exercise: the brittle cornerstone of type 2 diabetes treatment. Diabetologia 2008; 51(3) $398-401$

DOI: 10.3399/bjgp10X515025

\section{ADDRESS FOR CORRESPONDENCE}

\section{Peter Davies}

Keighley Road Surgery, Illingworth,

Halifax, HX2 9LL.

E-mail:npgdavies@blueyonder.co.uk 